atropine and duct decompression on the evolution of Diazinoninduced acute canine pancreatitis. Ann Surg. 1982;195:424-34.

7. Sahin I, Onbasi K, Sahin H, Karakaya C, Ustun Y, Noyan T. The prevalence of pancreatitis in organophosphate poisoning. Hum Exp Toxicol. 2002;21:175-7.

8. Harputluoðlu MM, Kantarceken B, Karincaoglu M, Aladag M, Yildiz R, Ates M, et al.Acute pancreatitis: an obscure complication of organophosphate poisoning. Human Exp Toxicol. 2003;22:341-3.

9. Goodale RL, Manivel JC, Borner JW, Liu S, Judge J, Li C, et al. Organophosphate sensitizes the human pancreas to acinar cell injury. An ultrastructural study. Pancreas. 1993;8:171-5.

10. Brahmi N, Blel Y, Kouraichi N, Abidi N, Thabet H, Amamou M. Acute pancreatitis subsequent to voluntary methomyl and dichlorvos intoxication. Pancreas. 2005;31:424-7.

11. Kandalaft K, Liu S, Manivel C, Borner JW, Dressel TD, Sutherland DE, et al. Organophosphate increases the sensitivity of human exocrine pancreas to acetylcholine. Pancreas. 1991;6:398-403.

12. Dressel TD, Goodale RL, Amerson MA, Borner JW. Pancreatitis as a complication of Anticholinesterase Insecticide Intoxication. Ann Surg. 1979;189:199-204.

13. Isselbacher KJ, Braunwald E, Wilson JD. Harrison's Principles of Internal Medicine Companion Handbook. $13^{\text {th }}$ ed. Singapore: McGraw-Hill, Inc 1995;514-6.

14. Andrén-Sandberg A, Dervenis C. Pancreatic pseudocyst in the $21^{\text {st }}$ century. Part II: natural history. JOP. 2004;5:64-70.

\section{PET positive lesions with increased SUV in post-surgical patients: where do we stand?}

\section{Introduction}

PET (Positron emission tomography) Scan using 18F fluorodeoxyglucose (FDG), a non invasive imaging technique, has been shown to be the most accurate investigation for the detection of local recurrences and distant metastases in patients with gastrointestinal malignancies. FDG is transported in to cells by glucose transporters (primarily GLUT 1) and phosphorylated and metabolically trapped by hexokinase. Cancer cells have been shown to have increased uptake of glucose and glycolytic enzymes and therefore preferentially uptake FDG, which then decays by position emission (1).This article is designed to report on the false - positivity of FDGPET scan in evaluation of recurrent or metastatic GI malignancies and SUVs (standardized uptake values) are examined to determine their significance in determining PET accuracy.

\section{Case Reports}

From June 2008 to August 2009 five cases of false positive PET lesions were identified in post operative patients who underwent PET- CT as part of follow-up. The details of five patients are:

\section{Case 1}

19 years old female diagnosed to have hepatoma right lobe of liver underwent right hepatectomy. After 15 months of followup, PET scan revealed PET positive lesion (SUV-5.2) in remnant liver along resected margin. Patient underwent non anatomical liver resection on January 2009. Histopathological examination revealed suture granuloma associated with foreign body giant cell reaction.

\section{Case 2}

52 years old female diagnosed to have carcinoma gall bladder underwent radical cholecystectomy on July 2008. After 11 months of follow up PET scan revealed soft tissue thickening in gall bladder fossa and infiltrating liver parenchyma with SUV of 4.9. Patient underwent non anatomical liver resection on June 2009. Biopsy revealed chronic inflammation with suture granuloma and fibrosis.

Case 3

64 years old female diagnosed to have carcinoma recto sigmoid underwent anterior resection. After 23 months of follow-up PET scan revealed a positive lesion in the tail of the pancreas (Figure 1 a,b). Patient underwent distal pancreatectomy with



Figure 1a: In case 3, CECT abdomen Showing SOL in tail of pancreas 


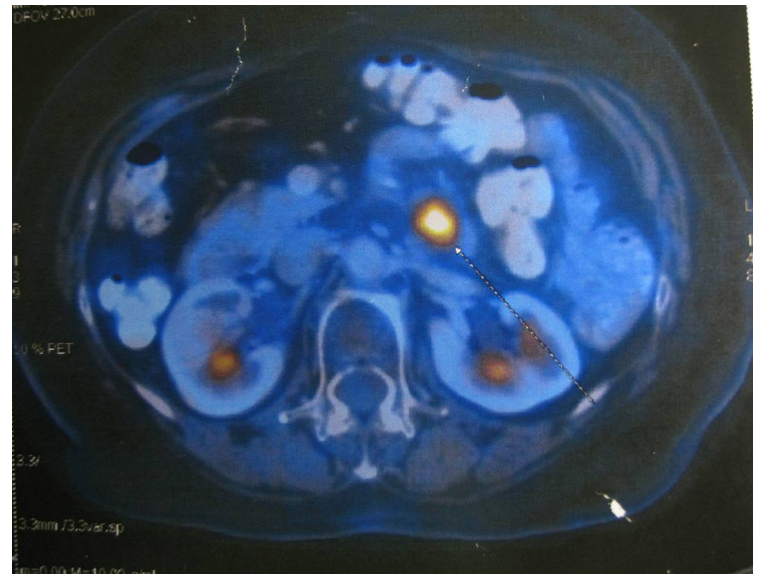

Figure 1b: PET scan showing FDG uptake in tail of pancreas

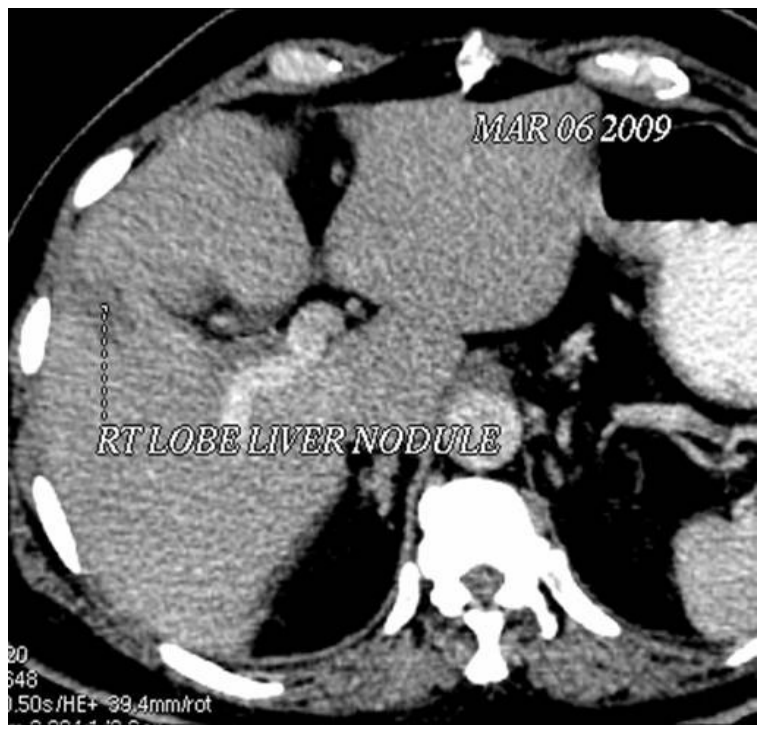

Figure 2a: In case 4, CECT abdomen showing SOL in right lobe of liver

Table 1: Clinical and surgical details

\begin{tabular}{|c|c|c|c|c|c|}
\hline Details & Case-1 & Case-2 & Case-3 & Case-4 & Case-5 \\
\hline$\overline{\text { Age (yrs) }}$ & 19 & 52 & 64 & 60 & 50 \\
\hline Sex & $\mathrm{F}$ & $\mathrm{F}$ & $\mathrm{F}$ & M & M \\
\hline Preoperative & Hepatoma & Ca Gall & Ca recto & Ca rectum & Intrahepatic \\
\hline diagnosis & right lobe & bladder & sigmoid & & cholangio carcinoma \\
\hline Surgery & $\begin{array}{c}\text { Right } \\
\text { hepatectomy }\end{array}$ & $\begin{array}{c}\text { Radical } \\
\text { cholecystectomy }\end{array}$ & $\begin{array}{l}\text { Anterior } \\
\text { resection }\end{array}$ & $\begin{array}{l}\text { Low Anterior } \\
\text { resection; }\end{array}$ & $\begin{array}{r}\text { Central hepatectomy } \\
\text { (HPE :Negative) }\end{array}$ \\
\hline $\begin{array}{l}\text { Postoperative } \\
\text { follow-up }\end{array}$ & 15 months & 11 months & 23 months & $\begin{array}{l}\text { Secondaries-liver. } \\
\text { segmentectomy } \\
\text { (Seg VII) done. } \\
8 \text { months follow-up }\end{array}$ & 18 months \\
\hline PET finding & $\begin{array}{l}\text { PET positive lesion } \\
\text { along resection } \\
\text { margin (SUV-5.2) }\end{array}$ & $\begin{array}{c}\text { PET positive lesion } \\
\text { in GB fossa (SUV - 4.9) }\end{array}$ & $\begin{array}{l}\text { PET positive lesion } \\
\text { in tail of pancreas } \\
\text { (SUV- } 7.1)\end{array}$ & $\begin{array}{c}\text { PET positive lesion } \\
\text { in right lobe of liver } \\
\text { (SUV-4.3) }\end{array}$ & $\begin{array}{l}\text { PET positive } \\
\text { lesion on both } \\
\text { sides of liver. } \\
\text { [SUV - 4.7] }\end{array}$ \\
\hline Procedure done & $\begin{array}{l}\text { Non anatomical } \\
\text { liver resection }\end{array}$ & $\begin{array}{l}\text { Non anatomical } \\
\text { liver resection }\end{array}$ & $\begin{array}{l}\text { Distal pancreatectomy } \\
\text { with splenectomy }\end{array}$ & Nil & Nil \\
\hline Biopsy & $\begin{array}{l}\text { Suture granuloma } \\
\text { associated with } \\
\text { foreign body giant } \\
\text { cell reaction. }\end{array}$ & $\begin{array}{l}\text { Chronic inflammation } \\
\text { with suture } \\
\text { granuloma with } \\
\text { fibrosis }\end{array}$ & $\begin{array}{l}\text { Chronic inflammation } \\
\text { with focal foreign } \\
\text { body reaction }\end{array}$ & - & - \\
\hline
\end{tabular}

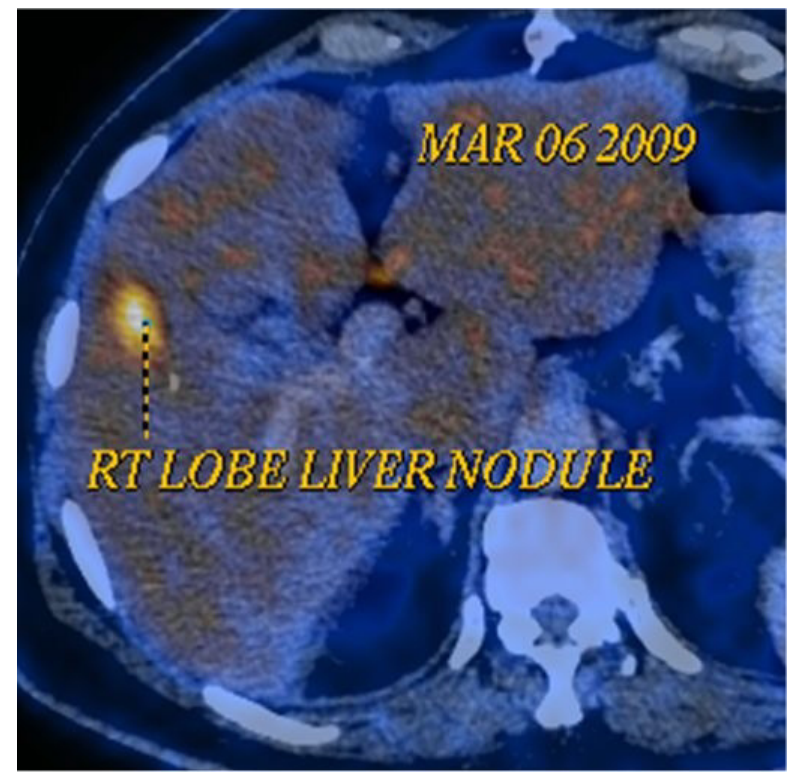

Figure 2b: In case 4, PET scan showing increased FDG uptake in right lobe of liver

splenectomy on May 2009. Biopsy showed sub acute to chronic inflammation with focal foreign body reaction.

\section{Case 4}

60 years old male diagnosed to have carcinoma rectum underwent low anterior resection. On follow-up diagnosed to have secondaries liver in Segment VII. Patient underwent segmentectomy. After 8 months of surgery, PET scans revealed PET positive lesion in the right lobe of liver and increased FDG uptake in right lobe of liver (Figure $\mathbf{2 b}$ ). As CECT did not 
reveal any lesion (Figure 2a) and CEA was normal patient was not subjected to surgery and is on regular follow-up.

\section{Case 5}

50 years old male diagnosed as a case of intrahepatic cholangio carcinoma underwent central hepatectomy. Histopathology revealed negative tumor margins. After 18 months, patient underwent PET scan, which showed increased uptake on both sides of liver. As previous histopathology revealed a negative margin patient is on regular follow-up.

All the patients underwent adjuvant chemotherapy. None of these patients received adjuvant radiotherapy. Case $4 \& 5$ were not subjected to surgery on clinical grounds (Table 1).

\section{Discussion}

PET scan is a new, important imaging technique in the diagnosis of malignancy and has the potential to greatly enhance preoperative staging of oncological patients. It is important to bear in mind that FDG uptake is not specific for malignancy. Inflammatory lesions can also exhibit 18-FDG uptake, presumably due to activated macrophages, and may be mistaken for malignancies. ${ }^{2,3}$ Granulomatous conditions such as sarcoidosis, fungal infections, tuberculosis and mycobacterium avium - intracellulare infection, can cause particular problems in the PET evaluation of pulmonary lesions or lymph nodes . ${ }^{4}$ Even inflammation related to therapeutic procedures, such as surgery or radiotherapy, can cause significant uptake. When clinically possible, it is usually wise to wait for atleast 6 months after the completion of radiotherapy before performing a PET study to avoid confusion by inflammatory uptake of FDG. ${ }^{5}$

Calculations of SUV provide quantification of the regional tracer uptake, and this method allows us to compare the tracer uptake in tumors from different patients. The SUV cutoff level for differentiation of malignant from benign lesions is approximately 3.5 (mci / weight in $\mathrm{kg}$ ) for metastases $>1 \mathrm{~cm}$ but differs between several tumors. Despite its popularity, conflict exist surrounding specific acquisition and limitation of the SUV such as uptake variability and its positive correlation to body weight have been reported ${ }^{6,7}$ We chose to focus on both SUV values and visual interpretation of FDG-PET. In our study, all 5 patients with false positive PET lesion had SUV value $>4.3$ again stressing the need to standardized SUV values.

In our study 5 patients underwent radical surgery for various GI malignancies, on subsequent follow up detected to have focal FDG uptake with PET scan. Salient features noted in PET scan were:

1) Focal uptake, No evidence of wide spread disease;

2) SUV > 4.3 in all patients;

3) PET scan performed $>8$ months following surgery (allowing post operative inflammation to subside)

With all these features the chance for local recurrence was presumed to be high and 3 patients were subjected for relook surgery with radical resection of PET positive lesion. Histopathological examination revealed chronic inflammation with focal foreign body reaction. Hence, subsequent 2 patients with PET positive lesion with no other clinical or imaging evidence of malignancy were not subjected for radical surgery, and they were subjected to close follow up. We would like to emphasize the fact that FDG uptake in post operative inflammation though described as time related phenomenon persists for more than 6 months and as long as 2 years as seen in one of our patients and larger prospective studies are needed to ensure appropriate standardization of SUV measurements. Positive PET lesions in atypical locations should be approached with caution and always should be biopsied before subjecting to radical surgery. We reemphasize the value of clinical knowledge in decision making and an awareness of the pitfalls of PET scan in achieving a correct diagnosis. The results of FDG-PET should be taken as complementary to other investigations and appropriate clinical knowledge should be utilized in decision making of patients with GI malignancies especially in post operative setting.

SELVAKUMAR ESWARAN, VIMALRAJ VELAYUTHAM, ARUNKUMAR KRISHNAN, JESWANTH SATYANESAN, SURENDRAN RAJAGOPAL.

Correspondence: Prof. R. Surendran,
Institute of Surgical Gastroenterology and Liver Transplantation,
Stanley Medical College Hospital,
Chennai-600001, Tamilnadu, India.
Email: $\underline{\text { stanleygastro@yahoo.com }}$

\section{References}

1. Arulampalam THA, Costa DC, Bomanji PJ, Ell PJ. The clinical application of positron emission tomography to colorectal cancer management. Q J Nucl Med. 2001;45:215-3

2. Schluter B, Grimm-Riepe C, Beyer W, Lubeck M, Schirren-bumann K. Clausen M. Histological verification of positive fluorine - 18 fluorodeoxyglucose findings in patients with differentiated thyroid cancer. Langenbecks Arch Surg. 1998;383:187-89. 
3. Kubota K. Matsuzawa T, Fujiwara T, Ito M, Hatazawa J. Ishiwata $\mathrm{K}$, Iwata R, Ido T Differential diagnosis of lung tumor with positron emission tomography: a prospective study. J Nucl Med. 1990;31:1927-32.

4. Kubota K, Yamada K, Yoshioka S, Yamada S, Ito M, Ido T. Differential diagnosis of idiopathic fibrosis from malignant lymphadenopathy with PET and F-18 fluorodexyglucose. Clin Nucl Med. 1992;17:361-3.

5. Landis K. Griffeth. Use of PET/CT scanning in cancer patients: technical and practical considerations. BUMC proceedings. 2005; 18:321-30

6. Haberkorn U. Strauss LG, Dimitrakopoulou A. Engenhart R. Oberdorfer F. Ostertag H, et al. PET studies of fluorodeoxyglucose metabolism in patients with recurrent colorectal tumors receiving radiotherapy. J Nucl Med. 1991;32:1485-90.

7. Graham MM, Peterson LM, Hayward RM: Comparison of simplified quantitative analyses of FDG uptake. Nucl Med Biol. 2000;27:647-55

8. SugawaraY, Zasadny KR, Neuhoff AW, et al. Reevaluation of the standardized uptake value for FDG. Variations with body weight and methods for correction. Radiology. 1999;213:521-5.

\section{Synchronous adenocarcinoma of the gall bladder and pancreas in a young}

\section{woman}

\section{Introduction}

Synchronous cancer of the upper gastrointestinal and biliary tract is rare, but is being increasingly detected due to newer advanced diagnostic techniques. Synchronous or metachronous cancers in the biliary system are often attributed to an abnormal pancreaticobiliary junction (APBJ), as a result of persistent reflux of pancreatic juice with subsequent biliary inflammation. ${ }^{1-4}$ However, it is very rare for gallbladder and pancreatic neoplasms to co-exist; in fact, only three previous reports mention this association..$^{5-7}$ We report a case of a young woman with synchronous cancers in the gallbladder and pancreas.

\section{Case Report}

A 35-year-old woman from rural north India presented with a six-week history of painless progressive jaundice, pruritis, vomiting, and, a right-sided abdominal lump. On examination, the patient was moderately nourished, and deeply icteric. Abdominal examination revealed hepatomegaly and a palpable distended gallbladder. The serum bilirubin was $15.6 \mathrm{mg} / \mathrm{dL}$, and serum alkaline phosphatase was 1526 IU/L [normal reference range: 0-300 IU/L). Other blood investigations including prothrombin time were normal. Ultrasound abdomen revealed an enlarged liver with normal echotexture and dilated extra- and intra-hepatic biliary radicals (IHBR). The gallbladder was distended and thick-walled, with an echo-free lumen. The pancreatic head was bulky and heteroechoic with suspicion of a mass lesion. CT scan showed a large mass (largest diameter $5 \mathrm{~cm}$ ) arising from the pancreatic head compressing the duodenum and stomach, with clear fat planes around it. The liver was enlarged, homogenous with multiple dilated intrahepatic biliary radicals (IHBR). The gallbladder was distended, with asymmetrical thickening of the wall, suspicious of malignancy. A moderate amount of free fluid was present (Figure 1). Upper GI endoscopy (side-viewing) showed a narrowed D2 lumen with extrinsic compression. There was no growth protruding from the ampulla. The mucosa around the ampulla was friable and coarse, and was biopsied. The histopathological examination revealed unremarkable duodenal mucosa with a few nests of malignant cells in the lower layers (Figure 2). With a probable diagnosis of synchronous gallbladder and pancreatic carcinoma with duodenal obstruction, exploratory laparotomy was planned. At laparotomy, we found a distended, hard, thick-walled gallbladder densely adherent to the porta and the common hepatic duct (CHD). There was also a large mass in the pancreatic head fixed to the retroperitoneum, with multiple enlarged peripancreatic lymph nodes. Two liters of free fluid was present in the peritoneal cavity. Due to the unresectable nature of the lesion, we performed a cholecystectomy, Roux-

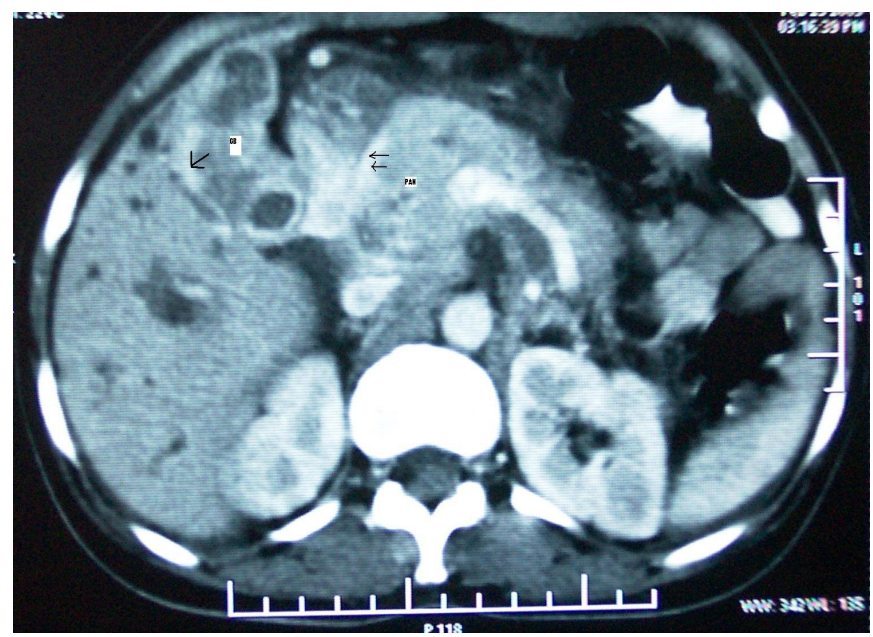

Figure 1: CT scan showing a large pancreatic mass (PAN) compressing the medial duodenal wall (double arrows). The gallbladder (GB) is also asymmetrically thickened (arrow) 